\title{
The "Smart Work" Myth: How Bureaucratic Inertia and Workplace Culture Stymied Digital Transformation in the Relocation of South Korea's Capital
}

Joon-Young Hur, Wonhyuk Cho, Geon Lee \& Sarah Hendrica Bickerton

To cite this article: Joon-Young Hur, Wonhyuk Cho, Geon Lee \& Sarah Hendrica Bickerton (2019) The "Smart Work" Myth: How Bureaucratic Inertia and Workplace Culture Stymied Digital Transformation in the Relocation of South Korea's Capital, Asian Studies Review, 43:4, 691-709, DOI: $\underline{10.1080 / 10357823.2019 .1663786}$

To link to this article: https://doi.org/10.1080/10357823.2019.1663786

\section{曲 Published online: 25 Sep 2019.}

Submit your article to this journal $\pi$

Џll Article views: 453

Q View related articles $\square$

View Crossmark data ¿

Citing articles: 1 View citing articles ¿ 


\title{
The "Smart Work" Myth: How Bureaucratic Inertia and Workplace Culture Stymied Digital Transformation in the Relocation of South Korea's Capital
}

\author{
Joon-Young Hura, Wonhyuk Cho $\mathbb{D}^{\mathrm{b}}{ }^{\mathrm{b}}$, Geon Lee ${ }^{\mathrm{c}}$ and Sarah Hendrica Bickerton ${ }^{\mathrm{b}}$
}

aKorea Institute of Public Administration; ${ }^{b}$ Victoria University of Wellington; 'Hanyang University

\begin{abstract}
Starting in 2012, the South Korean government has implemented a large-scale relocation of its central government agencies, which are now split between the existing capital city (Seoul) and a new administrative-capital city (Sejong). One of the most controversial aspects of the relocation has been the bureaucratic inefficiency caused by its split nature. ICT-enabled solutions, dubbed "Smart Work", were adopted to deal with this challenge, but have not been effective in avoiding inefficiency. In this article, we argue that different forms of organisational inertia created resistance to switching from traditional work routines to Smart Work's ICT-assisted equivalents. Various forms of inertia - psychological (anxiety around learning new technologies), cognitive (culture/norms in face-to-face work routines), technological (stickiness of pre-existing IT system), political (continued influence from elected officials), and resource allocation (success bias from previous digital government projects) - significantly influenced public managers' work practices in Sejong. These types of inertia, we argue, have reinforced face-to-face communication rather than digital communication, on-site visits rather than video-conferencing, and fixedtime work rather than flex-work. Our findings challenge dominant views from functionalist models of digital transformation and emphasise the importance of cultural congruency between workplace norms and technophilic business processes.
\end{abstract}

\section{KEYWORDS}

Bureaucracy; organisational inertia; digital transformation; e-government; public policy; capital city; Sejong City;

South Korea

\section{Introduction}

Seoul has been the capital city of South Korea (hereafter, Korea) for more than 600 years. The metropolitan area of Seoul, where most central government organisations have historically been located, is overpopulated and economically saturated. Around half of the country's population and businesses are concentrated in Seoul, which has contributed to demographic and economic inequality. As the Korean public gradually changed how it thought about the divide between Seoul and the rest of the country, the national government implemented a full-scale relocation of public bureaucracies away from the overpopulated city. The Korean government created an administrative-capital city, named Sejong City, and planned it as a self-administering multifunctional hub to achieve its economic, political and administrative 
goals. The new administrative-capital city was created in North Chungcheong Province, about 120 kilometres south of Seoul.

This large-scale project relocated more than 200 public and state-run organisations to Sejong City, while more than 100 organisations remain in Seoul. The scale of the relocation, as well as the resulting geographical dispersion of the central government, placed administrative organisations under considerable pressure to change their strategies and structure in such a way as to align with a new dynamic environment. To cope with the managerial challenges posed by the split-relocation of central government bureaucracies, the government formulated a series of "Smart Work" initiatives, which emerged as ICT-assisted solutions to the administrative problems of a split bureaucracy (Chun, 2005).

Since these Smart Work initiatives have been intended to apply to all organisations across the public sector, the ICT project itself is also a massive transformation. However, despite these ICT-enabled organisational strategies, the literature on change management and information system management suggests that institutionalised patterns of activities may lead to organisational inertia to maintain the status quo, and thus resistance to change (Constantinides \& Barrett, 2006; Hannan \& Freeman, 1984). The failure of ICT projects in public organisations due to such resistance to change has generated concern among academics, as well as among practitioners in the field, and subsequent research on this topic has indicated that many ICT-enabled organisational strategies are confronted with significant barriers to achieving expected managerial outcomes (Besson \& Rowe, 2012; Bloomfield \& Vurdubakis, 1997). There has been little research about public-sector organisations' ICTassisted managerial projects, however, and various dimensions of organisational inertia in this context have been understudied (Avgerou \& McGrath, 2007; Laumer et al., 2016).

This article aims to address this gap in the literature by analysing how radical and largescale organisational changes to a national government were implemented under the ICTenabled strategies that were intended to buffer the inefficiency-related impact of geographic dispersion. Korea's case of Sejong City is an excellent example for understanding the relocation of central government bureaucracy, and analysis of Korea's capital relocation is quite relevant to those Asian countries with similar challenges of hyper-concentration and lack of sustainability, such as the example of Indonesia, where the country's president recently announced the capital's relocation from Jakarta to Borneo. Further, the associated Smart Work project is an interesting testbed for seeing how organisational inertia operates in a context where faith in ICT infrastructure is both deep and widespread. This study's empirical basis is interview data from workers in the relocated central government bureaucracies, as well as documentary analysis of government publications, media reports and enacted legislation.

\section{Why a Split Bureaucracy? Political Disputes and their Consequences}

The administrative-capital city project, which was originally known as the capital cityrelocation policy, was initiated as a decentralisation strategy (Y. Choi, 2011). ${ }^{1}$ During the developmental period, which began in the 1960s, the Korean government tried to use economies of scale, concentrating the limited developmental resources in the big cities, and most evidently in its capital city, Seoul (Im \& Cho, 2008; Im \& Park, 2010; H. A. Kim, 2013; Park, 2003). The resulting socioeconomic pressure from a rapidly urbanised capital city has generated social costs such as an overheating housing market, a surging cost of living and 
serious congestion (Douglass, 2000; Hill \& Kim, 2000; Im \& Cho, 2010; Im, Cho, \& Porumbescu, 2011). However, a bigger concern than those urban problems was political dissent from people in less-developed regions, which has generated a push to deconcentrate the economic weight of Seoul (Campbell \& Cho, 2014; C. Kim, 2005). An imbalance in regional development, and the hyper-concentration of wealth in Seoul, have been recurrent policy issues for Korea (Chun, 2010; Kang, Cho, \& Jung, 2012; Kim \& Cho, 2014; Park, 2008). ${ }^{2}$

The administrative-capital city policy was able to be formulated because the way that Korean voters think about development has been gradually transformed: instead of being obsessed with the pace of economic growth, Koreans began to consider the distribution of benefits and favoured a reduction in regional inequalities (Chun, 2010; Hundt, 2015; Park, 2003; Suh \& Kwon, 2014). Therefore, the Sejong City project came to symbolise the notion of regionally balanced development. In this regard, the symbolic importance of the Sejong City project can be better understood in the context of the landscape of Korean politics, articulated along regional divides. Throughout the political development of modern Korea, party politics has not been well-established; instead, charismatic regional political leaderships such as Kim Dae-jung from Jeolla Province or Park Chung-hee from Gyeongsang Province have exercised a disproportionate impact on political outcomes (Kim \& Vogel, 2013; Y. S. Choi, 2017).

The (split-)relocation project was realised after a decade of constitutional controversies as well. Roh Moo-hyun included the capital relocation in his presidential campaign platform in 2002, and strong political support from voters who favoured this relocation was one of the reasons he was elected as president (see Hur, Kwon, \& Cho, 2015; Park \& Choi, 2011). However, the capital-relocation plan, and its subsequent enactment, faced a setback from the Constitutional Court, which ruled that the capital should stay put and that the relocation project was unconstitutional. As a result, Roh transformed the relocation into an "administrative-capital" project that aimed to move some central government bodies to Sejong City. ${ }^{3}$ In 2005, the bill creating the administrative-capital city was passed by the National Assembly. Sejong has not been granted legal status as the national capital, and the Blue House (the presidential residence and executive office) and the National Assembly of Korea remain in Seoul. ${ }^{4}$

\section{Impact of the Relocation}

The split-relocation started in 2012. The administrative-capital city project had a projected cost of $\$ 20$ billion, with around 40 per cent of the funds coming from central-government revenue (Choi \& Park, 2014). ${ }^{5}$ The government designated Sejong City as a special district, and established the Sejong Government Complex inside the district (Hur \& Kwon, 2016; Kwon, 2015). Sejong itself is a large district spanning more than 5 million $\mathrm{m}^{2}$, which is equivalent to 70 per cent of the size of Seoul. The Sejong Government Complex is one of the largest government administrative facilities in Korea, with 18 buildings on 596,283 $\mathrm{m}^{2}$.

As shown in Table 1, the relocation plan had three stages from 2012 to 2014, and then a new plan added another stage in 2015. In the first stage (2012), the focus was on relocating cabinet departments, and nine of the 18 cabinet departments moved in the first year. ${ }^{6}$ In the second stage (2013), the executive agencies and commissions were the 
Table 1. Number of Relocated Organisations and Employees by Type and by Relocation Period

\begin{tabular}{clll}
\hline & \multicolumn{1}{c}{$\begin{array}{c}\text { Cabinet } \\
\text { Departments }\end{array}$} & $\begin{array}{c}\text { Executive Agencies \& } \\
\text { Commissions }\end{array}$ & \multicolumn{1}{c}{$\begin{array}{c}\text { Policy Think Tanks \& Research } \\
\text { Institutes }\end{array}$} \\
\hline $1^{\text {st }}$ Stage (2012) & $\begin{array}{l}\text { 9 organisations } \\
\text { (5,595 employees) }\end{array}$ & $\begin{array}{l}\text { 6 organisations } \\
\text { (247 employees) }\end{array}$ & $\begin{array}{c}\text { No organisations in } \\
\text { this stage }\end{array}$ \\
$2^{\text {nd }}$ Stage (2013) & 6 organisations & 10 organisations & 2 organisations \\
& (4,302 employees) & (349 employees) & (618 employees) \\
$3^{\text {rd }}$ Stage (2014) & 3 organisations & 2 organisations & 12 organisations \\
& (1,606 employees) & (735 employees) & (2,574 employees) \\
Newly Planned Stage & 2 organisations & 2 organisations & 1 organisation \\
(2015-) & (1,529 employees) & (271 employees) & (353 employees) \\
\hline
\end{tabular}

focus, with 10 of these being relocated. Most of the public policy think tanks and research institutes were relocated in the third stage (2014).

Table 1 only presents the relocation of relatively larger organisations. In addition, there were many smaller public agencies or their satellite offices relocated from Seoul. Of the more than 400 public or state-run organisations that were previously located in Seoul, only 175 remain there. However, the most influential organisations, such as the Blue House, the National Assembly of Korea, the Ministry of Interior (formerly the Ministry of Public Administration), the Ministry of Foreign Affairs, the Board of Audit and Inspection, and the Financial Service Commission, remain in Seoul. By the end of 2014, the original relocation project was completed. A new phase of relocations began in 2015, and the list of relocated organisations is expanding (see Table 1).

\section{An Inefficient Split? Managerial Problems and the Smart Work Initiative}

After the split-relocation plan replaced the capital city-relocation plan, the problem of bureaucratic inefficiency caused by geographical dispersion was one of the most controversial issues (Lichá, 2015). In particular, the efficiency problems and the cost of travelling from Seoul soon attracted the attention of political leaders and decision-makers in the central government (Hur, Kwon, \& Cho, 2015; Lee, Choi, \& Park, 2005). The inefficiency challenges include concerns regarding interdepartmental collaboration, policy communication, emergency responsiveness and commuting difficulties (see Chun, 2010; Hur, Kwon, \& Cho, 2015; Hur \& Kwon, 2016; C. Kim, 2005; Lee, 2011). To respond to the inefficiency problem, the government needed to formulate efficiency-enhancement plans as an integral part of the relocation project. One of these was the Special Act on Construction of Sejong Self-Governing City.

Use of ICT and video-conferencing, which was later integrated into Smart Work, was first initiated in the Ministry of Public Administration and Security's "Basic Guidelines for Managerial Efficiency" in its "Relocation Plan of Central Government Institutes" in 2005. From this period, ICT-assisted solutions were the most important efficiency measures for the capital-relocation project. The term "Smart Work" first appeared when the Ministry of Public Administration and Security announced the "Strategies for Smart Work Promotion" in 2010, as part of a broader ICT-enabled reform, and set a target of 30 per cent of all public-sector workers to take part in Smart Work. ${ }^{7}$ The strategies constituted the "Digital Administrative Collaboration System Establishment Project", which aimed to enhance interoperability among government bodies. 
According to the government, the Smart Work paradigm is an ICT-enabled system that allows employees to work efficiently anytime and anywhere (Eom, Choi, \& Sung, 2014). By formulating the Smart Work initiative, the government expected that the bureaucracy would save commuting time and costs, improve the quality of the work environment, increase productivity, and achieve a good work-life balance. Smart Work also included an ICT-enabled provision for intra- and inter-organisational data-sharing and communication. ${ }^{8}$

As the split-relocation of the central government began, Smart Work was largely blended into the "Measures for Improving Administrative Efficiency" plan and became a dominant paradigm in the Sejong City project. For example, in May 2011, the Ministry of Public Administration and Security formulated a "Plan to Maintain Administrative Efficiency Related to Relocation to Sejong City", which was largely based on the Smart Work paradigm. This plan documented 10 measures under five goals, such as "Building Smart Work Centre" and "Realising Mobile Office". ${ }^{9}$ In this plan, the measures are focused on the use of ICT, based around Smart Work. ${ }^{10}$

In December 2012, the Ministry reported the creation of the "Future Plan to Maintain Administrative Efficiency in Relocated Organisations in Sejong City" (see Table 2). Table 2 summarises the government's own documentation (see Hur, 2013) concerning the goals for the Smart Work plan, and the actions and measures identified to achieve them. As can be seen, these actions and measures include for the most part technological solutions, with varying degrees of specificity.

The diffusion of the Smart Work paradigm continued in later government documentation and vocabulary. For example, the "Plan to Improve Administrative Efficiency of Relocated Organisations in 2013" repeatedly emphasised the use of information technology and video conferencing. The implementation of the Sejong City project has become more and more heavily reliant on ICT-enabled organisational transformation.

\section{Analytical Framework: An Organisational Inertia Perspective}

The split-relocation of a central government bureaucracy requires public agencies to undertake large-scale and radical organisational changes. There is a substantial literature on organisational transformations from a variety of perspectives, covering issues such as how changes occur and what constrains them in response to environmental threats and opportunities. An organisation needs to change continuously to align with a dynamic environment, but institutionalised routines can lead to organisational inertia and resistance

Table 2. Smart Work-based Plans to Maintain Administrative Efficiency Related to the Relocation (2012)

\begin{tabular}{|c|c|}
\hline Goal Statements & Required Actions and Measures \\
\hline I: Realising Remote Administration & $\begin{array}{l}\text { Establishing Video Conference Facilities and Encouraging Video Conferencing/ } \\
\text { Building Digital Collaboration System }\end{array}$ \\
\hline II: Realising Smart Administration & Building Trip-based Smart Work Centre/Realising Mobile Work Environment \\
\hline III: Minimising Citizen Inconvenience & Expanding Online Service for Citizens \\
\hline $\begin{array}{l}\text { IV: Improving Work Routines and } \\
\text { Working Conditions }\end{array}$ & Encouraging Flexible Work Arrangements/Transition to Smart Office \\
\hline $\begin{array}{l}\text { V: Improving Government Work } \\
\text { Efficiency }\end{array}$ & Diagnosing Level of Administrative Efficiency \\
\hline
\end{tabular}

Source: Ministry of the Interior and Safety (2013) 
to required changes (Besson \& Rowe, 2012; Cho, 2017; Hannan \& Freeman, 1984; Polites \& Karahanna, 2013). As technological development has resulted in calls to use ICT to facilitate significant organisational changes, recent work on organisational inertia has attracted considerable attention in the field of information systems-management (see Audzeyeva \& Hudson, 2016; Besson \& Rowe, 2012). As such, the organisational inertia perspective can be applied to the phenomena that this study analyses, namely Korea's mega-scale experiment in relocation and the technophilic strategies of the Smart Work initiatives.

Organisational sociologists have adopted the concept of inertia from physics as a metaphor for the stickiness of established patterns of thinking and activities in organisations (Brown \& Duguid, 2001; Cho \& Ho, 2018; Kaplan \& Henderson, 2005). They view organisational practices as bound by habits of behaviour and inertia that are gradually attached to work routines in organisations over time. When repeated within organisations, this becomes the pattern of daily activities. As a result, organisations remain rigid and resistant to change; they respond automatically based on past experience, and seek to maintain the status quo (Hannan \& Freeman, 1984; Huang et al., 2013; Rivard \& Lapointe, 2012).

Organisational inertia theory does not argue that organisations never change, but rather that inertia is determined by changes in a given environment (Kelly \& Amburgey, 1991). For example, when the speed of reorganisation is much slower than the rate at which environmental conditions change, there is a high level of organisational inertia (Hannan \& Freeman, 1984). That is, organisational inertia refers to the inability to enact necessary internal change in response to significant external change (Polites \& Karahanna, 2012). More broadly, organisational inertia is an overarching concept that encompasses personal commitments, financial investments and institutional mechanisms supporting the "current way of doing things" (Huff, Huff, \& Thomas, 1992).

There are various views on organisational inertia. For example, Starbuck, Greve and Hedberg (1978) view organisational inertia as a phenomenon of overly stable organisations. The implication for change management is that the established patterns of behaviour, or "habits of mind" (see Louis \& Sutton, 1991), can prevent an organisation from initiating changes even when poor performance may signal a need for such. On the other hand, Nelson and Winter (1982) argue that established routines in organisational activities offer the advantage of reproducibility, which is an essential element of organisational efficiency and stability - thus, paradoxically, the very characteristics that can generate efficiency in organisations also create resistance to changing inefficient practices.

There are different forms of organisational inertia, and previous studies focused on different aspects of the phenomenon. For example, Godkin and Allcorn (2008) focused on dimensions of insight inertia, action inertia and psychological inertia, while Gilbert (2005) emphasised the differentiation between resource inertia (failure to change resource-investment patterns) and routine inertia (failure to change the organisational processes that use those resource investments). Samuelson and Zeckhauser (1988) identified the main factors that contribute to inertia, which are sunk cost and social norms.

The difficulty for organisations in overcoming inertia when threatened with disruptive change has been a recent topic of scholarly inquiry, and this theoretical framework is useful in understanding the case of the Sejong City project and Smart Work initiatives. In particular, we apply the organisational inertia perspective in analysing the resilience of social structures and the processes by which structures were established under the capitalrelocation project. This study aims to identify the various forms of organisational inertia in 
this large-scale ICT-assisted project, and thereby to enrich theoretical understandings of organisational inertia in public institutions.

\section{Research Method}

Drawing on the aforementioned analytical framework, we analyse the work practices of the government officials involved in the capital-relocation project, link them with institutional patterns and commitments, and seek to understand the Sejong City project from different viewpoints. The qualitative data was collected from interviews with full-time-equivalent civil servants employed by the central government in Korea. The participants, 45 civil servants in the Sejong Government Complex, worked in the headquarters of six ministries located in Sejong: the Prime Minister's Office, the Ministry of Strategy and Finance, the Ministry of Land Infrastructure and Transport, the Ministry of Environment, the Ministry of Agriculture, Food, and Rural Affairs, and the Fair-Trade Commission. ${ }^{11}$

The data collection progressed through fieldwork phases during a period of three weeks, with the interviews lasting on average an hour and a half. The interviewees were from both managerial and non-managerial levels, including senior managers (grades 1-3: chief administrators, chief commissioners and deputy commissioners), middle managers (grade 4: secretary officials) and team members (grade 5: chief officials, grade 6: junior officials). We conducted semi-structured interviews that started from broad general questions about the tasks and roles of civil servants, and then shifted to more specific questions revolving around the changing nature of their work brought about by the relocation policy and introduction of Smart Work. We asked interviewees to describe their policy communication experiences (content and method by subject), the efficiency of their organisation, and how the government has responded to their concerns. Emergent themes in previous interviews were integrated into subsequent interviews.

These interviews were supplemented by government publications, observations from the researchers, and other sources of information about key developments in the project, as well as social interaction with different members of the government agencies in Sejong City. Field notes taken during both interviews and observations were transcribed immediately to preserve exact experiences as freshly as possible. As the emergent themes gave rise to more fruitful data, the researchers started to delve into them further while centring our thinking on key analytical concepts. In order to maximise the validity and reliability of our findings, systematic methods of data analysis were used, such as axial coding, selective coding, debriefing sessions, member checks and outlier analysis.

\section{How Smart Work Responded to the Split-Relocation}

Given the networked nature of the civil service, the organisations relocated to Sejong City need to work closely with those organisations that remain in Seoul. As parts of the bureaucracy were relocated to Sejong, the most prominent challenges emerged, not necessarily as a result of the relocation itself but rather due to the split nature of the relocation. President Roh's first initiative was the relocation of the entire body of the central government, but due to the complicated political and constitutional issues described above, the emblematic institutions of statecraft remained in Seoul. 
From the data we collected through the processes described above, we found that organisational inertia has affected the effectiveness of the Smart Work project during the Sejong City relocation. The relocated organisations and public officials in those organisations were unable to enact the expected internal change that Smart Work was intended to bring about, despite the significant external change of the large-scale splitrelocation to Sejong City. Our analysis identified five different forms of organisational inertia: psychological inertia, cognitive inertia, technological inertia, resource allocation inertia and political inertia.

\section{Psychological inertia: The anxiety of learning a new ICT-based system}

The public officials who were relocated to Sejong experienced stress and anxiety, as well as exhibiting a defensive mentality towards adopting technological changes, such as videoconferencing and remote work intranet use on mobile devices, that the Smart Work initiative was intended to institutionalise. They experienced a desire to feel in control, or anxiety towards losing control, over how they do their jobs, which resulted in a psychological preference for the status quo rather than learning how to use new technologies and worksystems under the Smart Work strategies. Even those public officials who acknowledged a need for change were resistant to change because of their anxiety over learning the new skills required to use the Smart Work technologies. In regard to psychological inertia, the officials expressed different levels of anxiety, from being seriously threatened by the ICT-assisted strategies to merely feeling less than enthusiastic about the change.

Public officials experienced psychological attachment, as evidenced in their commitment to previous work routines, and were reluctant to switch to the new technological alternatives suggested by Smart Work. This is at least partly because of the perceived (high) psychological costs of switching to the new work routine: these officials were psychologically uncertain about the new technology and demonstrated that it is risky to switch work routines due to anxiety around the resulting changes associated with new technology. Other reasons include the low level of perceived ease-of-use, as well as (a lack of) perceived usefulness of the technologies that Smart Work initiatives suggested. The public officials felt that Smart Work was not free from effort and did not feel that the use of Smart Work would increase their productivity in the current organisational context. Perceived losses loomed larger than gains: the small losses of switching from traditional work routines to Smart Work-based equivalents were perceived as very large. As a result, the officials felt there was no need to change the old and comfortable way of doing things. For example, a chief official in the Ministry of Land \& Transportation noted: "Non-face-to-face communication [via Smart Work system] causes difficulty in accurate conversation".

The massive relocation project with changes in many aspects of the lives of workers is itself a psychological context for the resistance (see Hur \& Lee, 2015). They have already experienced a large amount of stress from the relocation itself, which makes individuals psychologically more defensive in embracing further changes in work routines, but the nature of technological change often requires significant psychological effort. Further, being central in Seoul still matters psychologically, because the workers are emotionally attached to their past work routines. Thus, the emotions of the public officials about the Sejong City relocation and Smart Work initiative were fear, a feeling of loss or even anger. 
The psychological inertia experienced by relocated officials to Sejong resulted in both active and passive resistance to using Smart Work technology. For example, the newly introduced digital meeting system has rarely been used: some ministries have never used digital meeting rooms for meetings with National Assembly officials, preferring to travel. Other consequences include self-alienation from organisational life, with an "I just work here" attitude towards Smart Work strategies, as well as individuals' increased expectations of, or dependency on, managers or leadership to take care of their workers.

\section{Cognitive inertia: Culture, values and norms in face-to-face work routines}

The officials working in the Sejong Government Complex have shown evidence of managerial challenges in terms of communication with the organisations in Seoul, and overall inefficiency seems to have been a great problem due to counterproductive communications. Theoretically, all government workers should be able to use a Smart Work station and related technologies, as long as they are not required to be in face-to-face meetings, but they are often required to be physically in their offices or at important meetings because of social norms. Face-to-face interaction has been highly institutionalised in all aspects of central government organisations in Korea, and we found that cognitive inertia about the face-toface work routine prevails among public officials in Sejong.

The difference between cognitive inertia and psychological inertia is that cognitive inertia is more about a group's prevailing social values that are embedded in the work culture of the central government, whereas psychological inertia is more about an individual's preferences and/or feelings. A notable example we found during our interviews was that a supervisor's or peer's opinion about Smart Work would reinforce an individual's orientation. When a group or an individual in Sejong first uses the Smart Work system, they experience cultural conflicts with groups or individuals within their organisation, or even with the organisation itself. For example, a junior officer in the Ministry of Environment noted, "We rarely use the Smart Work centres. When someone works there [Smart Work centre], everyone thinks they are lazy".

The Smart Work system provides, albeit not fully, remote access to administrative materials and management systems, allowing workers to work from home or at Smart Work centres. This technological tool is provided by the Smart Work project so that relocated workers can maintain the same or a similar level of work efficiency to that prior to the relocation, without having to travel from Sejong to Seoul. However, in a survey of central government workers conducted in 2015, more than 80 per cent of employees perceived that the organisational culture (and the routinised working practices embedded in that culture) did not allow for working in Smart Work centres (National Information Society Agency, 2015). As such, there is significant under-use of the system.

This analysis does not imply that face-to-face communication is less effective or less efficient than ICT-assisted communication, however. Studies actually show that face-toface communication is a very efficient method, especially when information cannot be codified, when implicit information plays an important role, or when face-to-face interaction can facilitate socialisation and learning (Asheim, Coenen, \& Vang, 2007; Ho \& Cho, 2017; Purvanova \& Bono, 2009; Storper \& Venables, 2004). Therefore, preference for face-to-face communication can result from a rational choice by public officials in relocated organisations. Further, we acknowledge that this preference for 
face-to-face meetings is not solely a Korean phenomenon. The main point of our finding in terms of cognitive inertia is that the pre-existing work routines based on norms around face-to-face communication in the Korean bureaucracy are a source of resistance to switching to the Smart Work-based work processes.

Central government workers in Korea, as a group, have built their work culture, and resulting work habits, around traditional practices of work. New technologies such as video-conferencing and use of mobile devices under the Smart Work system were seen as violations of these traditional values and meanings shared by public officials, which in turn produced a culture-based resistance to change. This shows that significant organisational change can face resistance from organisational members if there are no cultural changes and validation in work groups.

Therefore, one of the lessons from the Smart Work project is that the cultural aspect of change should be dealt with prior to the implementation of the change. However, it is equally notable that the work culture in Korea's central government is very difficult to alter, since it is deeply institutionalised and work relationships are also shaped under that culture. Long-term strategies to deal with cognitive inertia are therefore needed to gain desired outcomes of wider change. Managers and decision-makers in the central government underappreciated the cognitive aspect and possible cultural conflict, and as a result, the ICT-facilitated changes intended for the Smart Work strategies have not been fully achieved.

\section{Technological inertia: The stickiness of existing IT systems}

The technologies arising from the Smart Work strategies were - paradoxically - both new and old. For example, Smart Work's On-NARAeM system was expected to improve interoperability and PC-based video conferencing, but this system is merely a renaming of existing digital platforms. Previously these were called the Business Process System, and later the Government Knowledge Management Center, before they were renamed On-NARAeM. This system aimed to support ICT-assisted communication and collaboration, as well as to routinise cloud-based work processes. Although this system is a renovated platform, there is technological inertia from the pre-existing ICT system.

The technologies used in the Smart Work system were "new wine in old wineskins", and as a result, the system has been considerably under-used by public officials in Sejong. For example, statistics from the Ministry of the Interior show that less than 11 per cent of its employees use the On-NARAeM system for digital communication (Ministry of the Interior, 2015). The encouragement of digital meetings through established ICT tools was no more than a stated declaration, because basic e-communication infrastructure was based on oldstyle ICT systems that are not user-friendly in a modern technological setting. Mobile/PCbased individual e-communication, rather than old-style digital conferencing rooms, is another important tool, but the development of these features was delayed because of the desire to build them under existing technology. Besides, the renovated On-NARAeM was launched years after the relocated agencies were already suffering from communication issues with this system - in 2015 for holding e-meetings among the central government bureaucracy, and in 2016 also for communication with the National Assembly.

The "stickiness" of pre-existing ICT infrastructure also discouraged the use of innovative and well-used technologies. Korea has one of the world's most developed broadband and internet systems, and consistently ranks at the top of the ITU's scale in this 
regard. Video-communication services developed in the private sector, such as Skype, Zoom and FaceTime, have been available and widely used for more than a decade. Technical capability or readiness was therefore not an issue in Sejong: rather, there was technological inertia in the pre-existing ICT system. In interviews, public officials explained that they failed to use more user-friendly and better-designed e-communication tools because of compatibility issues with pre-existing systems that were not sufficiently modern. They also said that they were not allowed to use third-party e-communication services such as Skype, or other mobile messengers, for work purposes due to information-security concerns. Management insisted that workers only use the Smart Work system for intra- or inter-organisational e-communication, which, as mentioned above, was resisted due to perceptions that it was not easy to use and the usefulness of the pre-existing technology.

Another example of the "new wine in old wineskins" problem of the Smart Work system is the "Working from Home" strategy and related technology. ${ }^{12}$ Remote work, or working from home, has been almost impossible for public officials, not only because of culturally driven concerns, but also because of technological issues resulting from pre-existing and ageing ICT structures with a lack of modern capability and questionable sustainability. While it is arguably a necessity in the public sector to have strict rules and regulations around data security and privacy, the way the government developed the Working from Home technology was akin to "shoehorning" modern layers to an aged and nearly incompatible ICT structure, which made even simple activities, such as opening emails and accessing intranets, simply impossible or extremely complicated. The Working from Home system was thus not fit for purpose, technologically. Similar problems were found in "Mobile Work", another major part of the Smart Work strategy. The catchphrase of "work anywhere, anytime" illustrates what the Mobile Work system was intended to achieve, but the technology for enabling it was built on the ageing technological infrastructure that only supported "work only here, only at this time".

\section{Resource-allocation inertia: Success bias and myth of e-government}

In implementing the relocation project and the accompanying Smart Work strategies, the appropriateness of an ICT-facilitated solution to underlying managerial problems has never been questioned. This is despite the fact that there is little evidence of improved efficiency as a result of e-government features. However, after the Smart Work strategy was first suggested in 2005 as an appealing solution to the inefficiency of the split-relocation, resources to combat these inefficiencies have been predominantly allocated to Smart Work. In the interviews, we found a success bias among public officials who were overconfident about what technology can do for public organisations.

This resource-allocation inertia seems to originate from the previous success of Korea's e-government. ${ }^{13}$ Korea has one of the best records of developing e-government in the world (Im et al., 2014a; Lee \& Porumbescu, 2019; Rana et al., 2015). The UN Global E-Government Survey found that since 2004 Korea has been consistently acknowledged by the international community as one of the top five countries for e-government. The experience of success in government-led centralised planning for e-government in Korea has generated (over)confidence in centrally planned ICT-enabled reforms. ${ }^{14}$ In this context, Smart Work can be seen as a "silver-bullet" myth, shared by decision-makers: a solution 
that could eliminate all problems of inefficiency. This belief in an ICT-assisted solution became gradually diffused as an appropriate way of dealing with the problems of the splitrelocation and led to a failure to find other innovative managerial alternatives to deal with the issues that were predicted in the Sejong project.

We found from our interviews that other alternatives and measures were proposed by managers and policy-makers to deal with the inefficiency of the split-bureaucracy, but because of the resource-allocation inertia towards ICT-assisted solutions of Smart Work, other ideas failed to emerge in any strategies or plans due to a lack of resources. For example, the central government proposed a large-scale job analysis from a sample of 12,000 employees, and from there to formulate substantive action plans, but this was not done because resources were overwhelmingly allocated elsewhere, namely to Smart Work.

Due to this resource-allocation inertia (see also Besson \& Rowe, 2012; Gilbert, 2005; Im et al., 2014b), based on decision-makers' overconfidence bias towards e-government success, the lack of substantive measures for the split-relocation was largely underrepresented in policy circles. As a result, instead of questioning the fundamental assumptions of Smart Work strategies, policy-makers responded to criticism by allocating even more resources to Smart Work.

\section{Political inertia: Continued influence from the Blue House and National Assembly}

In interviews we conducted in Sejong, public officials noted that the organisations that remain in Seoul, most notably the Blue House and the National Assembly, are still the most powerful and influential in Korea. These organisations can directly affect the formulation and implementation of policies in all government departments, regardless of where those departments are located. Face-to-face contact has been institutionalised in this context, as traditionally Korea has maintained a system of strong presidential control over the entire body of government, both the bureaucracy and the legislature.

We found that political inertia from power networks within the government affected the implementation of Smart Work strategies as well as relocated organisations' behavioural patterns. The disproportionate decision-making leverage of Seoul-centred policy communication has led to incomplete deconcentration of government activities. Sejong City is an inconvenient place to work, given that the most powerful organisations remain in Seoul, and the institutionalised face-to-face communication pattern is difficult to switch to a Smart Work routine. As mentioned above, we found that senior public servants have resisted changes such as video-conferencing, but they have also maintained Seoul-based work routines even if this requires spending a great deal of time commuting between Sejong and Seoul. For example, a junior official in the Ministry of Planning and Finance noted,

Section heads and managers have frequent business trips. About half of a week. On that occasion, about half of the staff move together. Therefore, the approval is delayed, and communication is abstracted. Top-ranked public officers such as ministers and viceministers often stay outside of their office, which in turn affects subordinates in their division sequentially.

In particular, high-ranking officials in Sejong prioritise face-to-face access to organisations such as the National Assembly and the Blue House, because informal communication among them has become deeply institutionalised. Efforts to replace this communication 
with remote work-stations and video-conferencing have brought little result, because both the Sejong officials and the people they want to communicate with share a belief that important decisions should be made through face-to-face communication. Even if some important decisions are officially approved in a seemingly effective video-conference, those decisions have mostly already been discussed and agreed on through previous informal face-to-face communications. Conversely, what is discussed in a virtual e-meeting often only reaches final agreement after a subsequent informal lunch or dinner, outside of official communications. This continues to have an inertial impact on work routines in the relocated organisations.

The political inertia of the government's Seoul-centred informal and formal networks has created an inability to respond to urgent policy issues that require timely decisions and close collaboration among the bureaucracy. Analysts even refer to this as "Sejong City Risk", or the malfunction of standard operating procedures in the government's emergency management. For instance, the spread of Severe Acute Respiratory Syndrome (SARS) in 2015 illustrated the problem of the infection-control system for the Ministry of Health and the Centres for Disease Control and Prevention. Intergovernmental communication was very inefficient during this time because, at an early stage of the outbreak, decision-makers in Seoul misjudged the seriousness of the situation due to a lag in reports from lower-level officials who were not making good use of the Smart Work system (Korea Economic Daily, 2015). SARS spread most seriously in Seoul, but while the Ministry of Health and its taskforce were working in Sejong, debriefing occurred in person in Seoul. So there was a lack of timely communication and an inability to respond promptly to developments.

\section{Discussion and Concluding Remarks}

The split-relocation of the central government is one of the most disruptive policies in Korean history, and the accompanying Smart Work strategies are also one of the government's largest ICT-assisted managerial innovations. Apart from the debate as to whether the ambitious new city can drive growth outside an overpopulated Seoul, or only result in a waste of government money, the relocated organisations face serious managerial challenges. We analysed how the technophilic strategy in the Smart Work paradigm was adopted and implemented, and discussed what the consequences have been, adopting perspectives from organisational inertia theories.

Smart Work was supposed to be an advanced mode of work, enabling people to work efficiently and flexibly without geographical or time constraints, but what has actually occurred is that different forms of organisational inertia have reinforced face-to-face communication rather than electronic communication, on-site visits rather than videoconferencing, and on-site work rather than flex-work. There has been significant resistance to switching from traditional work routines to Smart Work's new technological solutions, and public managers in Sejong hold fast to these traditional work routines, even though it takes much time and money for them to do so in the wake of the relocation.

Our findings challenge dominant views in the literature from the rational and functionalist models of ICT-assisted organisational transformation by tackling or questioning the assumptions of those models. Understanding the phenomenon from an inertia perspective is important for practice as well, because it helps to formulate realistic expectations of the ways, and the extent to which, ICT-enabled transformation is implemented in organisations, 
and helps to develop capabilities to assess the potential outcomes that large-scale ICT projects can bring about under different social circumstances.

The Sejong project indicates that if new institutions are devised after work patterns have become institutionalised for individuals and workgroups, those new institutions should be designed in consideration of the culture encompassing them. In addition, the rationale for new institutions should be clearly specified. The proposed results of the Smart Work paradigm are more likely to be achieved when we seriously consider the inertial impact on implementation when longer-term strategies are formulated. The lesson from resourceallocation inertia in the Smart Work project is that it is important to be able to question the fundamental assumptions of a mega-project and be cautious about government's success bias.

This study shows that ICT-enabled reforms have been greatly affected by myths in their formulation and implementation (Bekkers \& Homburg, 2007; Bretschneider, 2003). One such e-government myth is that ICT-enabled reforms will produce a better government that is more responsive, more cohesive and more client-oriented (Janssen, Charalabidis, \& Zuiderwijk, 2012). Myths of ICT-enabled reform strategies often begin with an optimistic description of the progress possible in an information society. These are strong beliefs about technological progress, which is trusted to dramatically improve the capacity to innovate government and governance (Hellberg \& Hedström, 2015; Sagarik et al., 2018). Based on our case study, we can claim that when institutions collide, individuals are not likely to accept the new institution, no matter how innovative it may be. To put it another way, we found that individuals tend to follow existing institutions when values (e.g. power relationships) are internalised.

This study is also expected to contribute to knowledge about large-scale relocations of central governments. In many countries, especially in post-colonial Asia, national bureaucracies are located in overpopulated regions, with the resulting divide between the centre and the periphery becoming a major issue. The Sejong City case is a good illustration of experiences that other nations should pay attention to in formulating their own strategies to deconcentrate the demographic and economic weight of a capital city. It must be noted that this study focuses on intra- and inter-governmental management and organisational dynamics in Smart Work initiatives, and future studies should expand this to also analyse the nature of communication between government agencies and the private sector, as well as the impact of the split-relocation of central bureaucracies on this inter-sector relationship.

\section{Notes}

1. The idea to relocate the capital from Seoul to a regional area was not new. For example, in the late 1970s, the military regime attempted to build a new capital city, mostly for defence/security purposes.

2. Previous attempts to moderate this concentration have proven unsuccessful. The strategically created satellite cities around Seoul have failed to reduce the level of concentration, and instead have led to an expansion of the metropolis, complicating the problem and further intensifying the disproportionality (Hur, Kwon, \& Cho, 2015). Other measures, such as tax incentives for business investments in less developed and farther-flung regions, have also had little success (C. Kim, 2005). 
3. Scepticism about managerial efficiencies arose, since the Sejong City plan was not about simply relocating the capital city's functions to another city, but rather about splitting the bureaucracy.

4. This split-relocation of an administrative-capital city is a unique experiment, and it is difficult to find comparable cases in other countries. When new capital cities such as Berlin (Germany), Putrajaya (Malaysia), Astana (Kazakhstan), Abuja (Nigeria) and Brasilia (Brasil) were created, these new centres almost completely replaced the functions of the old capitals. The case most similar to the Sejong City project is Putrajaya, but the geographical context is very different because Putrajaya is only 36 kilometres from Kuala Lumpur.

5. This project includes a plan to accommodate industrial and educational clusters, which is estimated to increase the city's population to 500,000 within 20 years (Ha, 2011).

6. The 36 relocated cabinet departments, executive agencies and commissions have more than 10,000 employees. The largest organisation among those relocated is the Ministry of Land, Infrastructure and Transport, which has more than 1,200 employees. Other large organisations (with more than 700 employees) include the Ministry of Strategy and Finance, the Ministry of Education, Science, and Technology, the Ministry of Health and Welfare, and the National Tax Service.

7. The Korean Communications Commission has also been involved in the Smart Work paradigm, but gradually the Ministry of Public Administration and Security has taken more control.

8. Korea has highly developed ICT industries, and the government's approach in building smart cities (formerly ubiquitous cities) has influenced the emergence of the Smart Work concept.

9. I: Realising Remote Administration (Encouraging Video Conferencing/Building Digital Collaboration System/Efficiency-Enhancement in Communication with National Assembly - Video Communication), II: Realising Mobile Administration (Building Smart Work Center/Realising Mobile Office), III: Building Smart Work Infrastructure (Establishing Cloud-Computing-Based Office Environment/Transition to Smart Office), IV: Minimising Citizen Inconvenience (Expanding Online Service for Citizens), V: Providing Convenient Commuting (Encouraging Flexible Work Arrangements/Providing Commuting Bus).

10. There are currently 356 video-conferencing rooms in the central government, and 291 facilities in local governments.

11. These ministries interact actively with other organisations such as the National Assembly and the Blue House located in Seoul. Therefore our interviews mainly dealt with public officials in Sejong rather than those in Seoul in that they did not experience a drastic change in policy communication with the National Assembly or the Blue House. We targeted all the ministries located in Sejong at that time, such as the Prime Minister's Office, the Ministry of Strategy and Finance, the Ministry of Land Infrastructure and Transport, the Ministry of Environment, the Ministry of Agriculture, Food, and Rural Affairs, and the Fair Trade Commission.

12. In addition to inefficiency reduction, the Smart Work paradigm was promoted as a solution to the problem of work-life balance (Hur \& Kwon, 2016). The reality, however, of the Sejong Government Complex is that most employees still have to leave their families behind in Seoul. Smart Work centres became integral to the national strategy to create a better work-life balance, but these centres may be incompatible with Korean workplace culture. In Korea a collective work spirit is emphasised, so many government workers are required to be present in their office. In this institutional context, Smart Work is considered "Lazy Work", rather than efficient work.

13. This tendency was reinforced in 2013 when the Smart Work paradigm was gradually annexed into the Government 3.0 paradigm.

14. In Korea's e-government development, ICT infrastructure has been developed by government plans from the 1980s onward, such as the Korean Backbone Computer Network project that 
furnished the communications and information network for the public sector. In the 1990s, the Informatisation Promotion Act was enacted for e-government development with a huge Promotion Fund and also established the Chief Information Officer system. In the early 2000s, Korea passed the Promotion of Digitalisation of Administrative Work for E-Government Realisation Act, which is a comprehensive piece of legislation focusing on e-government, and the E-Government Roadmap was planned and implemented.

\section{Acknowledgments}

The authors are grateful for the data support from the Korea Institute of Public Administration (KIPA). This article makes use of research material produced by the KIPA and has been authorised for use according to KIPA's regulations on the ownership and use of said research material. All errors remain the responsibility of the authors.

\section{Funding}

Sarah H. Bickerton's contribution to this article is partially supported by Faculty Research Grant [Grant ID: 221494] from the Victoria Business School; Wonhyuk Cho received partial support from the National Research Foundation of Korea through a grant [NRF-2017S1A3A2065838] to work on this project.

\section{ORCID}

Wonhyuk Cho (D) http://orcid.org/0000-0001-7607-6480

\section{References}

Asheim, B., Coenen, L., \& Vang, J. (2007). Face-to-face, buzz and knowledge bases: Sociospatial implications for learning, innovation, and innovation policy. Environment and Planning C: Government and Policy, 25(5), 655-670.

Audzeyeva, A., \& Hudson, R. (2016). How to get the most from a business intelligence application during the post implementation phase? Deep structure transformation at a UK retail bank. European Journal of Information Systems, 25(1), 29-46.

Avgerou, C., \& McGrath, K. (2007). Power, rationality and the art of living through socio-technical change. MIS Quarterly, 31(2), 295-315.

Bekkers, V., \& Homburg, V. (2007). The myths of e-government: Looking beyond the assumptions of a new and better government. Information Society, 23(5), 373-382.

Besson, P., \& Rowe, F. (2012). Strategizing information systems-enabled organizational transformation: A transdisciplinary review and new directions. Journal of Strategic Information Systems, 21(2), 103-124.

Bloomfield, B. P., \& Vurdubakis, T. (1997). Visions of organization and organizations of vision: The representational practices of information systems development. Accounting, Organizations and Society, 22(7), 639-668.

Bretschneider, S. (2003). Information technology, e-government and institutional change. Public Administration Review, 63(6), 738-741.

Brown, J. S., \& Duguid, P. (2001). Knowledge and organization: A social-practice perspective. Organization Science, 12(2), 198-213.

Campbell, J. W., \& Cho, W. (2014). Two faces of government-business relations during South Korea's developmental period. Korean Comparative Government Review, 18(1), 47-66.

Cho, W. (2017). Change and continuity in police organizations: Institution, legitimacy and democratization. Korean Journal of Policy Studies, 32(1), 149-174. 
Cho, W., \& Ho, A. T. (2018). Does neighborhood crime matter? A multi-year survey study on perceptions of race, victimization and public safety. International Journal of Law, Crime and Justice, 55, 13-26.

Choi, S., \& Park, Y. (2014). A study on the process of policy change of Sejong City: Focusing on the advocacy coalition framework and multiple streams framework. Korean Journal of Policy Studies, 23(4), 371-412.

Choi, Y. (2011). Measures for ensuring the national efficiency of Sejong City. Chungbuk: Chungbuk Research Institute.

Choi, Y. S. (2017). Kim Dae-jung and the persistence of anti-communist hegemony in South Korea. Asian Studies Review, 41(2), 299-316.

Chun, Y. (2005). The administrative central city and the efficiency of national management. Proceedings of State Affairs Conference of Korean Association for Public Administration.

Chun, Y. (2010). A critical review on Sejong City project in the context of administrative governance system. Social Science Studies, 17(1), 75-95.

Constantinides, P., \& Barrett, M. (2006). Large-scale ICT innovation, power and organizational change: The case of a regional health information network. Journal of Applied Behavioral Science, 42(1), 76-90.

Douglass, M. (2000). Mega-urban regions and world city formation: Globalisation, the economic crisis and urban policy issues in Pacific Asia. Urban Studies, 37(12), 2315-2335.

Eom, S., Choi, N., \& Sung, W. (2014). The use of smart work in Korea: Who and for what? Paper presented at $15^{\text {th }}$ Annual International Conference on Digital Government Research.

Gilbert, C. G. (2005). Unbundling the structure of inertia: Resource versus routine rigidity. Academy of Management Journal, 48(5), 741-763.

Godkin, L., \& Allcorn, S. (2008). Overcoming organizational inertia: A tripartite model for achieving strategic organizational change. Journal of Applied Business and Economics, 8(1), 82-95.

Ha, H. (2011). A study on the political adoptability of public policy: The case of the amended Sejong City Act. Korean Comparative Government Review, 15(3), 343-362.

Hannan, M. T., \& Freeman, J. (1984). Structural inertia and organizational change. American Sociological Review, 49(2), 149-164.

Hellberg, A., \& Hedström, K. (2015). The story of the sixth myth of open data and open government. Transforming Government: People, Process and Policy, 9(1), 35-51.

Hill, R. C., \& Kim, J. W. (2000). Global cities and developmental states: New York, Tokyo and Seoul. Urban Studies, 37(12), 2167-2195.

Ho, A. T. K., \& Cho, W. (2017). Government communication effectiveness and satisfaction with police performance: A large-scale survey study. Public Administration Review, 77(2), 228-239.

Huang, H., Lai, M., Lin, L., \& Chen, C. (2013). Overcoming organizational inertia to strengthen business model innovation: An open innovation perspective. Journal of Organizational Change Management, 26(6), 977-1002.

Huff, J. O., Huff, A. S., \& Thomas, H. (1992). Strategic renewal and the interaction of cumulative stress and inertia. Strategic Management Journal, 13(S1), 55-75.

Hundt, D. (2015). Neoliberalism, the developmental state and civil society in Korea. Asian Studies Review, 39(3), 466-482.

Hur, J. (2013). Analysis on current policy communication practices by the decentralization of central administrative organ into Sejong City and improvement measures. Seoul: KIPA.

Hur, J., \& Kwon, H. (2016). An exploratory study theorizing factors hindering "work-life balance (WLB)": Applying grounded theory to central government civil servants in Sejong City, Korea. Korean Journal of Public Administration, 54(2), 1-30.

Hur, J., Kwon, M., \& Cho, W. (2015). Administrative inefficiency of geographically dispersed central government bodies: Case study on Sejong City in Korea using grounded theory. Korean Public Administration Review, 49(3), 127-159.

Hur, J., \& Lee, G. (2015). A study on the effect of relocation of workplace on public managers' job turnover intention: Focusing on the moderate effect of relocation to Sejong City. Korea Public Administration Journal, 24(3), 65-90. 
Im, T., \& Cho, W. (2008). Decentralization and economic growth in Korea. Korean Journal of Policy Studies, 23(1), 49-71.

Im, T., \& Cho, W. (2010). Time factors in policy performance: The Korean government's economic crisis management in 2008. Korean Journal of Policy Studies, 25(2), 103-128.

Im, T., Cho, W., \& Porumbescu, G. (2011). An empirical analysis of the relation between social spending and economic growth in developing countries and OECD members. Asia Pacific Journal of Public Administration, 33(1), 37-55.

Im, T., Cho, W., Porumbescu, G., \& Park, J. (2014a). Internet, trust in government and citizen compliance. Journal of Public Administration Research and Theory, 24(3), 741-763.

Im, T., Lee, H., Cho, W., \& Campbell, J. W. (2014b). Citizen preference and resource allocation: The case for participatory budgeting in Seoul. Local Government Studies, 40(1), 102-120.

Im, T., \& Park, J. (2010). Korea's experiences with development: Revisiting MDGs from a time perspective. Korean Journal of Policy Studies, 25(3), 125-145.

Janssen, M., Charalabidis, Y., \& Zuiderwijk, A. (2012). Benefits, adoption barriers and myths of open data and open government. Information Systems Management, 29(4), 258-268.

Kang, Y., Cho, W., \& Jung, K. (2012). Does decentralization matter in health outcomes? Evidence from 22 OECD unbalanced panel data for 1995-2005. International Review of Public Administration, 17(1), 1-32.

Kaplan, S., \& Henderson, R. (2005). Inertia and incentives: Bridging organizational economics and organizational theory. Organization Science, 16(5), 509-521.

Kelly, D., \& Amburgey, T. L. (1991). Organizational inertia and momentum: A dynamic model of strategic change. Academy of Management Journal, 34(3), 591-612.

Kim, B.-K., \& Vogel, E. F. (Eds.). (2013). The Park Chung Hee era: The transformation of South Korea. Cambridge: Harvard University Press.

Kim, C. (2005). Multi-functional administrative city and measures for securing national efficiency. Proceedings of the Spring Conference of Seoul Association for Public Administration.

Kim, H. A. (2013). Industrial warriors: South Korea's first generation of industrial workers in post-developmental Korea. Asian Studies Review, 37(4), 577-595.

Kim, N., \& Cho, W. (2014). Agencification and performance: The impact of autonomy and result-control on the performance of executive agencies in Korea. Public Performance \& Management Review, 38(2), 214-233.

Korea Communication Commission. (2012). A study on the service competition strength and infrastructure improvement for smart work. Seoul: KCA.

Korea Economic Daily. (2015). Sejong City hazards: MERS response in chaos and the bureaucratic screw is loose. Korea Economic Daily.

Kwon, Y. (2015). Sejong Si (City): Are TOD and TND models effective in planning Korea's new capital? Cities, 42, 242-257.

Laumer, S., Maier, C., Eckhardt, A., \& Weitzel, T. (2016). Work routines as an object of resistance during information systems implementations: Theoretical foundation and empirical evidence. European Journal of Information Systems, 25(4), 317-343.

Lee, D. (2011). Political leadership during a policy shift: The effort to revise the Sejong City plan. Korean Journal of Policy Studies, 26(1), 1-19.

Lee, J., \& Porumbescu, G. A. (2019). Engendering inclusive e-government use through citizen IT training programs. Government Information Quarterly, 36(1), 69-76.

Lee, M. H., Choi, N., \& Park, M. (2005). A systems thinking approach to the new administrative capital in Korea: Balanced development or not? System Dynamics Review, 21(1), 69-85.

Lichá, A. (2015). Songdo and Sejong: Master-planned cities in South Korea. Working Paper. Urban Affairs Department, Sciences Po, Paris.

Louis, M. R., \& Sutton, R. I. (1991). Switching cognitive gears: From habits of mind to active thinking. Human Relations, 44(1), 55-76.

Ministry of the Interior. (2015). Report on On-NARAeM system usages. Seoul: MOI.

Ministry of the Interior and Safety. (2013). Smart work guideline for administrative efficiency. Seoul: MSPA. 
National Information Society Agency. (2015). Smart work user survey research: Public sector and private sector. Seoul: NIA.

Nelson, C., \& Winter, S. (1982). Organizational capabilities and behavior: An evolutionary theory of economic change. Cambridge: Harvard University Press.

Park, B. G. (2003). Territorialised party politics and the politics of local economic development: State-led industrialization and political regionalism in South Korea. Political Geography, 22(8), 811-839.

Park, B. G. (2008). Uneven development, inter-scalar tensions and the politics of decentralization in South Korea. International Journal of Urban and Regional Research, 32(1), 40-59.

Park, Y. S., \& Choi, J. W. (2011). Study on the typology and functions of policy brokers in the advocacy coalition framework: The case of Sejong City. Korean Journal of Public Administration, 49(2), 103-125.

Polites, G. L., \& Karahanna, E. (2012). Shackled to the status quo: The inhibiting effects of incumbent system habit, switching costs and inertia on new system acceptance. MIS Quarterly, 36(1), 21-42.

Polites, G. L., \& Karahanna, E. (2013). The embeddedness of information systems habits in organizational and individual level routines: Development and disruption. MIS Quarterly, 37 (1), 221-246.

Purvanova, R. K., \& Bono, J. E. (2009). Transformational leadership in context: Face-to-face and virtual teams. Leadership Quarterly, 20(3), 343-357.

Rana, N. P., Dwivedi, Y. K., Williams, M. D., \& Weerakkody, V. (2015). Investigating success of an e-government initiative: Validation of an integrated IS success model. Information Systems Frontiers, 17(1), 127-142.

Rivard, S., \& Lapointe, L. (2012). Information technology implementers' responses to user resistance: Nature and effects. MIS Quarterly, 36(3), 897-920.

Sagarik, D., Chansukree, P., Cho, W., \& Berman, E. (2018). E-government 4.0 in Thailand: The role of central agencies. Information Polity, 23(3), 343-353.

Samuelson, W., \& Zeckhauser, R. (1988). Status quo bias in decision making. Journal of Risk and Uncertainty, 1(1), 7-59.

Shimizu, K., \& Hitt, M. A. (2005). What constrains or facilitates divestitures of formerly acquired firms? The effects of organizational inertia. Journal of Management, 31(1), 50-72.

Starbuck, W. H., Greve, A., \& Hedberg, B. (1978). Responding to crises. Journal of Business Administration, 9(2), 111-137.

Storper, M., \& Venables, A. J. (2004). Buzz: Face-to-face contact and the urban economy. Journal of Economic Geography, 4(4), 351-370.

Suh, C. S., \& Kwon, S. H. (2014). Whither the developmental state in South Korea? Balancing welfare and neoliberalism. Asian Studies Review, 38(4), 676-692. 